\title{
Enunciação e autoria via comunicação alternativa e interlocução mediadora
}

\section{Enunciation and authorship through alternative communication and dialogue mediation}

Ana Beatriz Machado de Freitas*

Centro de Educacional Professor Anísio Teixeira

Goiânia - Goiás / Brasil

RESUMO: A comunicação denominada alternativa e / ou ampliada compõe-se de recursos de tecnologia assistiva que possibilitam expressão ou ampliação da capacidade comunicativa a pessoas que apresentam comprometimento significativo na linguagem verbal. Entretanto, a comunicação estabelecida nem sempre transcende o responder funcional sob limitado repertório. $\mathrm{O}$ artigo discorre sobre linguagem e sujeito da enunciação, suas relações com o desenvolvimento da autoria e implicações na constituição subjetiva de sujeitos não falantes. Fundamenta-se em princípios das abordagens enunciativo-discursiva, de Bakhtin, e históricocultural do desenvolvimento humano. Salienta-se o papel e a responsabilidade do mediador, seja quando, por sua interlocução, favorece o ampliar da comunicação significativa e autora, seja, contrariamente, quando restringe essas possibilidades.

PALAVRAS-CHAVE: comunicação não verbal, subjetividade, mediação.

ABSTRACT: Augmentative and / or Alternative Communication is a field of Assistive Technology which encompasses resources to help people with severe speech and language impairments to express themselves. However, communication does not always overcome functional responses within a limited linguistic repertoire. The article discusses language and subject of enunciation, their relations with authorship development and as well as implications to subjective constitution of the non-speech people. Theoretically it was based on the Bakhtin's enunciativediscursive principles and on the cultural historical theory of human development. It emphasizes the role and responsibility of the mediator when he contributes, through his dialogue, to increase a significant communication and authorship or, conversely, when he can restrict these possibilities.

KEYWORDS: non-verbal communication, subjectivity, mediation.

*bianadefreitas@ig.com.br 


\section{Introdução}

A expressão sujeito da enunciação soa redundante. Ser sujeito implica capacidade de enunciar, sobretudo enunciar-se, expressar com singularidade o seu verbo, linguagem. Esta, entretanto, é costumeiramente reduzida à capacidade de verbalização, a qual é superestimada. À fluência verbal é associado bom desenvolvimento intelectual, partindo-se do pressuposto: fala é expressão do pensamento. Dessa lógica, pode-se deduzir: comprometimentos na expressão verbal implicariam prejuízo cognitivo e o desempenho educacional seria prejudicado, uma vez que ausências ou déficits importantes de oralização não permitiriam o alcance de certas etapas para a conquista de aprendizados mais complexos. Haveria também necessidade de uma educação especial e de intervenção de especialistas, como fonoaudiólogo e psicopedagogo.

Pesquisas embasadas na abordagem histórico-cultural do desenvolvimento humano têm chamado a atenção para o quanto as interações sociais, mediações e diálogos não são apenas influentes, mas constitutivos do desenvolvimento, tanto cognitivo quanto da subjetividade, pois à medida que as significações se ampliam para o sujeito, tornam-se parte de seu conhecimento e história e são produzidos sentidos pessoais em que a emocionalidade e um modo autor de conhecer e expressar(-se) estão presentes.

Padilha (2001), Passos (2007), Gomes e González Rey (2008) e Orrú (2009) exemplificam e assim denunciam, a partir de estudos de caso, o quanto pessoas com deficiência, particularmente aquelas com deficiência intelectual e / ou na expressão verbal por comprometimentos como autismo e lesões cerebrais, são cerceadas quanto às possibilidades de desenvolvimento da linguagem. Impregnados pelo modelo médico, pela histórica influência da psicologia comportamental e da visão estruturalista de língua / linguagem, os procedimentos em educação especial e terapêutica para esse alunado, no que concerne ao desenvolvimento de linguagem, orienta-se por diretrizes e protocolos de levantamento de repertório linguístico e comprometimentos (mais que as competências). Segue-se, então, a seleção de vocabulário e recursos para desenvolver a capacidade comunicativa por vias consideradas alternativas à fala ou que a ampliam; daí as denominações CSA (Comunicação Suplementar e / ou Alternativa) ou CAA (Comunicação Alternativa e Ampliada).

A literatura especializada emprega os termos CSA ou CAA para designar recursos e procedimentos que deem possibilidades de comunicação para pessoas que, em razão de alguma doença ou deficiência, não consigam se expressar e interagir por meio da fala. É considerada uma tecnologia assistiva e abrange 
língua de sinais, gestualidade, códigos, expressões faciais, símbolos gráficos, desenhos, fotos, pictogramas, bem como programas e sistemas computadorizados específicos (PELOSI, 2000; MANZINI; DELIBERATO, 2006; ORRÚ, 2009).

Apesar da abrangência do conceito, as denominações CAA e CSA aparecem no contexto da educação especial associadas com maior ênfase aos recursos figurativos, como as imagens e pictogramas, seja, como definem Manzini e Deliberato (2006), sob alta tecnologia (recursos computacionais) ou baixa, por exemplo, a confecção de cartões de figuras e de um suporte (denominado prancha), feito de madeira, plástico, papelão ou acrílico sobre o qual palavras, letras, figuras e / ou símbolos são colocados. Os recursos, como salientam Orrú (2009), Passos (2009) e Pelosi (2000), são personalisados quanto à forma, dimensão, textura, conteúdo (quantidade, repertório) e posicionamento, pois devem atender a necessidades particulares de comunicação, considerando-se a cognição, o contexto e o repertório de linguagem do sujeito, bem como as condiçōes visuais e motoras deste (exemplo: posicionar figuras no suporte de forma que o usuário possa identificar e indicar cada uma - e ser compreendido - por meio de um gesto ou olhar dirigido).

Questionamos, entretanto, se os recursos de CAA seriam suficientes para constituir um sujeito que enuncia desejos, emoções, necessidades, opiniōes, ideias, sugestôes, discordâncias, argumentaçôes; enfim, sujeito que expressa um pensar a partir de relaçôes de diálogo significativas das quais derivaram aprendizagem que, de acordo com Vygotsky (1998), é condição para o desenvolvimento. Como ressaltam Passos (2007) e Orrú (2009), a CAA muitas vezes é empregada a partir de um enfoque que supervaloriza a aquisição das estruturas e convençôes do idioma, respostas sequenciadas e aspectos sensoriais e psicomotores, vistos como desenvolvimento / mudanças / respostas de comportamento frente ao estímulo, recurso, pré-requisito ou ambiente estruturado.

Em consonância com as autoras citadas e fundamentos da perspectiva histórico-cultural, problematizamos: que concepção de verbo / linguagem está aí presente? Responder adequadamente - isto é, ao que o outro espera ou propôs como repertório de respostas - significa desenvolvimento da capacidade comunicativa e autoria na enunciação? O que se perspectiva quanto à importância e capacidade (potencial) de enunciação autora para um sujeito com ausência ou limitaçôes na fala? Sob que condições poderia-se transcender (ou não) da mera expressão linguística à autoria? 
Acreditamos que a discussão de tais questionamentos seja relevante para (re)pensar intervenções pedagógicas e terapêuticas, sobretudo quanto ao papel, mais do que os recursos, da interlocução para com esse sujeito.

\section{Enunciação, pensamento e autoria}

Sujeito da enunciação é uma expressão presente na obra de Bakhtin (1995), na referência ao falante, locutor, aquele que faz uso dos enunciados do idioma. Esse uso, no entanto, não implica assujeitamento, pois até mesmo as convenções idiomáticas e valoraçôes semânticas apresentam mudanças, as quais decorreram de um contexto sociopolítico e histórico em que os falantes exprimem e veiculam significações e valores. Assim,

não são palavras o que pronunciamos ou escutamos, mas verdades ou mentiras, coisas boas ou más, importantes ou triviais, agradáveis ou desagradáveis, etc. A palavra está sempre carregada de um conteúdo ou de um sentido ideológico ou vivencial (BAKHTIN,1995, p. 95) [Grifo do original].

É o que ocorre, na atualidade, por exemplo, no que concerne à informática. Vocábulos referentes a computadores, internet e celulares não faziam parte das conversas dos falantes das grandes cidades há vinte ou trinta anos; hoje aparecem naturalizadas, sobretudo pelos falantes mais jovens. A era das navegações on-line ampliou a significância do verbo navegar. As caravelas de outrora são hoje os computadores e nossos nautas contemporâneos cruzam continentes graças à rede (pescadores?) de comunicação virtual por mares culturais, parafraseando Camões, nunca dantes navegados. Discute-se até o chamado internetês, se seria uma subversão da língua padrão ou uma variação a caminho de ser considerada adequada, portanto, legítima no contexto dialógico da informática.

Outros termos (significantes) têm sua significação alterada ao longo da história e à medida que os idiomas se interpenetram há ressignificação pelos falantes. Ecclesia, por exemplo, significa, em grego clássico, assembleia, entendida como reunião de pessoas (CUNHA, 1997). Atualmente, em português, encontramos ampliação do significado do termo assembleia, e de ecclesia também se originaram os vocábulos latinos “igreja” e eclesiástico. A ideia original de igreja era, pois, de reunião de pessoas.

Mencionamos tais exemplos para ilustrar que modificações na língua (idioma) ocorrem em curto ou longo prazo e estão vinculadas a uma cultura 
cujo desenvolvimento, peculiaridades e influências são propagados e modificados pelas relações sociais, na dialogia de seus falantes. Dessa compreensão, infere-se papel ativo do sujeito ator e autor, o que supóe, sobretudo na autoria, um enunciar que denote pensamento para além da repetição do verbo.

Quando "a fala se torna intelectual e o pensamento verbalizado (...) a própria criança necessita da palavra e procura ativamente assimilar o signo pertencente ao objeto, signo esse que serve para nomear e comunicar" (VYGOTSKY, 2001, p.131). Desse entrelaçamento - pensamento e linguagem - decorre e destaca-se a função intrapsicológica do signo, ou seja, seu papel na constituição das funções cognitivas complexas, ditas superiores, e do comportamento:

Inicialmente a fala segue a ação, sendo provocada e dominada pela atividade. Posteriormente, entretanto, (...) surge uma nova relação entre palavra e açáo. Nesse instante a fala dirige, determina e domina o curso da ação; surge a função planejadora da fala, além da função já existente da fala, de refletir o mundo exterior (VYGOTSKY, 1998, p. 31).

O mundo exterior concerne, sobretudo, às interações sociais nas quais e /ou a partir das quais o sujeito aprende. E o aprendizado "adequadamente organizado resulta em desenvolvimento mental e põe em movimento vários processos de desenvolvimento que, de outra forma, seriam impossíveis de acontecer" (VYGOTSKY, 1998, p.101).

Padilha (2001) acrescenta:

Vygotsky explicita que a palavra adquire sentido nas relações sociais entre pessoas e que é na interação, em forma de drama, que as funções psicológicas superiores se desenvolvem. Toma o conceito de drama de George Politzer (1928-1998), para quem a experiência propriamente humana constitui um drama: o que nos acontece são sempre acontecimentos dramáticos e dramáticas são as nossas intenções, os nossos desejos; o que pensamos sobre nós mesmos, pensamos em termo dramáticos (PADILHA, 2001, p. 21).

Nessa temática, dialogamos com a psicopedagoga Alicia Fernandez que, embora sob um referencial predominantemente psicanalítico, tece pertinentes consideraçóes que vem ao encontro dos postulados acima, visto que disserta sobre a dinâmica intersecção: aprendizagem (sempre a partir de um outro) e autoria de pensamento. 
Diferentemente do respirar ou de outra função orgânica que vem programada de modo instintivo, andar de bicicleta, caminhar, escrever e os demais conhecimentos requerem uma aprendizagem. É precisamente por isso que os processos de aprendizagem são construtores de autoria. O essencial do aprender é que ao mesmo tempo se constrói o próprio sujeito (FERNANDEZ, 2001, p. 31).

O pensamento, para essa autora, "não pode ser autônomo, definir suas próprias normas desvinculadas do desejo e da dramática inconsciente, já que operar ancora-se no desejar." (FERNANDEZ, 2001, p. 91). Ainda que inconscientes, observa, o desejo e os dramas derivam-se de relaçóes sociais de significância, tanto as relações ensinante-aprendente quanto ao que concerne a como e por quem o sujeito é / foi significado no mundo (como é nomeado, classificado, posto em um lugar simbólico na família, na escola, nas instâncias sociais, como é qualificado, que atributos são mais ou menos ressaltados).

Voltando à terminologia bakhtiniana, caberia a analogia: o enunciar(-se) do sujeito tem a ver com as condiçôes (sociopsicológicas, compreendendo-se a psique como socialmente constituída) sob as quais ele é enunciado. Depreendese o importante papel da linguagem e dos falantes / locutores na constituição do sujeito, não somente intelectual, mas, de modo mais amplo, da subjetividade / autoria, da expressão do próprio logos. Não por acaso esse termo, logos, em grego, refere-se tanto à palavra quando ao saber. Palavra que era fomentada e discutida em praça pública na Grécia Antiga (CHAUÍ, 1995), de modo que, no debate, o verbo fosse intelectualmente (re)elaborado e ressignificado.

Até aqui nos referimos à linguagem palavra e aos falantes. Questionariase, então: pessoas não-falantes estariam assujeitadas, pela impossibilidade de enunciar / (-se)? Qual o seu lugar (social, psíquico) de enunciação e as perspectivas de desenvolvimento intelectual e subjetivo?

Compreendemos os termos locutor e sujeito da enunciação em uma perspectiva enunciativo-discursiva, em que o sujeito não é somente falante / usuário de sistemas linguísticos ou de formas de comunicação (verbais e não verbais), mas, dialeticamente, à medida que dialoga, compreende, questiona $\mathrm{e}$ ressignifica enunciados. Assim, nos contextos dialógicos, portanto sociais, intersubjetividades se constituem e potencialmente abrem, modificam e / ou ampliam "espaços" de ressignificação das enunciações, do pensamento e da autoria.

Muitas pessoas, por motivos diversos (doenças, deficiências, acidentes), não falam ou apresentam limitações significativas na expressão verbal. São enunciadas, mas nem sempre é potencializada sua enunciação. Requerem, 
portanto, recursos que lhes permitam exteriorizar ou ampliar seu potencial de expressão linguística e logos. Esses recursos são conhecidos na educação especial como Comunicação Suplementar e/ou Alternativa (CSA) ou Comunicação Alternativa e Ampliada (CAA).

\section{Comunicação não verbal e enunciação autora: o importante papel do mediador}

A referência à comunicação alternativa diz respeito aos sistemas e / ou recursos de comunicação alternativos e / ou suplementares à fala, utilizados de maneira preponderante por aqueles que apresentam capacidade de verbalização comprometida. No Portal de Ajudas Técnicas para Educação, da Secretaria de Educação Especial do MEC, no fascículo voltado a recursos para comunicação alternativa, é salientado que:

Vários podem ser os sistemas alternativos para a comunicação. A criança ou jovem pode usar um tabuleiro de comunicação que contenha símbolos gráficos, como fotos, figuras, desenhos, letras, palavras e sentenças, e construir sentenças ao apontar para as fotos, desenhos ou figuras estampadas, de modo a se fazer entender no ambiente escolar ou social. Há ainda sistemas que utilizam a tecnologia, avançados sistemas computadorizados e softwares específicos (MANZINI; DELIBERATO, 2006, p. 4)

Entre os software, um dos mais difundidos é o Picture Communication Symbols (PCS), criado pela fonoaudióloga norte-americana Roxanna Mayer Johnson em 1981 (ORRÚ, 2009; MAYER-JOHNSON, 2011). O dicionário de PCS, presente no programa (software) Boardmaker contém cerca de 4500 caracteres. Os símbolos pictóricos (pictogramas) são atrativos pelas cores e similaridade com o real que expressam; permitem, assim, melhor compreensão tanto para o usuário com limitações na fala quanto para seus interlocutores.

Recursos considerados de baixa tecnologia, por seu baixo custo e familiaridade com materiais do cotidiano escolar, também podem e devem ser utilizados e seu uso sugere maior êxito, visto facilitarem a identidade / familiaridade e manipulação. Fotos gravuras, imagens, miniaturas e objetos do cotidiano também são importantes e mesmo fundamentais. A confecção de uma prancha de comunicação suplementar e / ou alternativa, como ressaltam pesquisadores da área, é personalizada e precisa partir das intenções e necessidades comunicativas do sujeito (PELOSI, 2000; MANZINI; DELIBERATO, 
2006; ORRÚ, 2009). Importa acrescentar que concomitante ou alternativamente, conforme o sujeito, outras vias comunicativas podem ser manifestas e desenvolvidas, como a gestualidade e movimentos da face. (Exemplo: piscar rapidamente duas vezes diante de uma pergunta pode ser uma ato combinado com os interlocutores para significar "Sim").

A expressão de linguagem, desejos e conhecimentos é assim permitida e facilitada e, por conseguinte, a ampliação da autonomia, da capacidade comunicativa e das interações sociais. Nesse processo, mediante interlocuções, é potencializado o desejo de conhecer e aprender e novos centros de interesse dele emergem. Em decorrência, tende-se à ampliação do vocabulário e ao desenvolvimento das funções psíquicas superiores, entre elas a atenção, memória e linguagem. A função do recurso alternativo (seja figurativo, gestual / corporal, computacional) é, pois, potencialmente idêntica à da palavra. Dissemos potencialmente porque:

embora a CSA seja significativa para o ato de ensinar e interagir com pessoas que se encontram nas situações mencionadas, para haver eficácia, é preciso que seu usuário apresente motivação para se comunicar, demonstrada por meio do desejo de estabelecer uma comunicação interativa; que haja aceitação e envolvimento de sua parte e das pessoas que o acompanham na utilização de determinado sistema de comunicação, haja atenção aos estímulos do contexto em que o usuário está inserido - pois há necessidade de que a pessoa tenha certa habilidade cognitiva e nível de acuidade visual - e haja envolvimento de outros profissionais que o acompanham em seu desenvolvimento e tratamento (ORRÚ, 2009, p. 70-71).

Os avanços na comunicação e na interatividade dependerão, portanto, não apenas dos recursos, mas em muito das condições clínicas, cognitivas e motivacionais do sujeito e da participação dos envolvidos.

Acrescentamos, contudo, que nem um diagnóstico clínico aparentemente pouco promissor de êxito na comunicação, como o quadro autístico, nem a desatenção ou inicial fala de interesse / motivação podem ser fatores de não investimento na comunicação. Muitas vezes essas características estão presentes ou mais fortemente acentuadas exatamente pela falta ou pouco investimento e perseverança em estabelecer interatividade e comunicação, no que estão envolvidos não somente recursos técnicos, mas a qualidade da mediação / mediador.

Pesquisadores como Padilha (2001), Cupolillo e Freitas (2007), Passos (2007), Gomes e González Rey (2008), Freitas (2009) e Orrú (2009) 
desenvolveram estudos qualitativos em que acompanharam pessoas com deficiência (ou com características ou suspeita de deficiência). Entre as hipóteses ou diagnósticos figuram autismo, dificuldade na alfabetização, deficiência intelectual, atraso no desenvolvimento e lesão cerebral. Nos casos relatados, a ausência ou prejuízo quantitativo e qualitativo na linguagem estavam presentes. Entretanto, mediante intervenções em que os pesquisadores investiram na intersubjetividade pesquisador-sujeito participante, ou seja, no estabelecimento de um vínculo suficiente de confiança, motivador e desafiador para o desenvolvimento (intelectual, acadêmico, emocional, social e de autonomia), os sujeitos demonstraram mudanças significativas na expressão da linguagem, não somente na articulação e vocabulário mas também no que se refere ao conhecimento de mundo, das situações e significações da cultura e contexto a que pertencem, o que veio a se refletir na enunciação do $e u$, expressa em iniciativas, questionamentos, discordâncias, e nem sempre verbais. Padilha (2001) bem exemplifica:

Pegar cadernos, folhear, apontar, aproximar as mãos do rosto para anunciar que vai dar um palpite, uma opinião... sorrir, mudar o corpo de lugar para adequar ao espaço... chegar mais perto, distanciar-se... bater na mesa para deixar clara a sua vontade, ou para confirmar o que havia dito... tudo isso é Bianca marcando seu lugar, negociando com o outro que também está ocupando um lugar social (...). É Bianca dando-se a entender, assumindo que seu corpo também indica, também anuncia e enuncia. (PADILHA, 2001, p.113).

Menos importa conhecer e deficiência (disartria, autismo, paralisia cerebral). Importa, primeira e principalmente, conhecer a pessoa, observá-la e escutá-la em suas manifestações de linguagem / expressão, procurar interagir com ela, entrando em interlocução para, assim, mediar enunciações e um sujeito que enuncia. $\mathrm{O}$ mediador não deve ser mero estimulador, portador de um conteúdo ou um modelo a copiado. Se assim o for, a aprendizagem tenderá a ser constituída por um prisma funcionalista: o sujeito pode adquirir e repetir o ensinado, mas apenas como significantes desprovidos de sentido ou, ainda que compreendidos, não se convertem em elementos suficientemente significativos para o desenvolvimento da autoria.

Segundo González Rey (2004, p. 2), "o homem responde a sistemas de significação que têm valor apenas dentro dos marcos da cultura em que atua. Essa característica integra as emoções dentro de espaços simbólicos e conduz ao que temos definido como sentido subjetivo...". Entretanto, nem sempre 
o aprendizado de significações potencializa ou configura-se autoria, pois muitas vezes ele requer prioritariamente respostas adaptativas e repetição.

Padilha (2001) e Passos (2007) observam, respectivamente, que as avaliações clínicas de linguagem e os programas pedagógicos de educação especial costumam centrar-se na aquisição da fala ou de elementos e convençōes do código linguístico, e não na expressão subjetiva do comunicar e no desenvolvimento do sujeito simbólico, ou seja, do ato / autoria de significar e ressignificar. Mesmo no que tange ao aprendizado formal do idioma, os níveis fonológico e morfossintáticos costumam ser privilegiados em detrimento da semântica e da pragmática. Ainda impera o modelo médico em que sobressai a importância em diagnosticar desvios em relação a padrões de normalidade. A esse respeito, comenta Passos (2007):

São avaliados os níveis da linguagem expressiva e receptiva (...) e posteriormente comparados à norma lingüística ideal tida como condição para boa comunicação. Os erros ou resultados desviantes são inventariados e servem como base para o plano terapêutico, aos quais se encaixam perfeitamente aos manuais de procedimentos de intervenção, já que o sentido do sintoma é único, fixo e estável (PASSOS, 2007, p. 32).

Dessas avaliações decorrem planejamentos para favorecer a chamada aquisição de linguagem, em geral em hierarquia, dos termos considerados mais fáceis para os mais difíceis (Ex: letras- sílabas- dissílabas; letra-palavra-frase).

$\mathrm{Na}$ realidade, o sujeito está imerso em um contexto linguístico historicamente determinado, com situações sociais e práticas culturais veiculadas e constituídas por discursos ora mais ora menos complexos, ora mais ora menos informais, às vezes privilegiando-se o senso comum e o coloquial, outrora o artístico e o poético, o denotativo e científico, dentre tantas possibilidades de variaçōes, leituras, diálogos e interpenetração quantitativa e qualitativa. Assim, se há uma hierarquia para a aquisição verbal de fonemas devido à maturação biológica (órgãos fonoarticulatórios) e se é passível de planejamento de uma sequência para facilitar, quando necessário, essa aquisição, o mesmo não ocorre quanto à linguagem. Essa não é propriamente adquirida (as convenções do idioma é que o são), pois não é externa ao sujeito. A linguagem é matéria-prima de sua constituição pessoal e sociocultural, uma vez que, por várias maneiras e recursos, os enunciantes expressam, produzem e veiculam significaçôes da cultura e contexto que configuram as subjetividades individuais. 
Nesse processo está envolvida a história de aprendizagem, e com veemência as relações com os ensinantes. O que predomina? Vínculos que condicionaram e assim aprisionaram o sujeito em modelos a serem respondidos-repetidos? Ou vínculos que favorecem o pensamento e um enunciar autor a partir das significações? Afinal,

A inteligência não se constrói no vazio: ela se nutre de experiência de prazer pela autoria. Por sua vez, nas próprias experiências de aprendizagem, o sujeito vai construindo a autoria de pensamento e o reconhecimento de que é capaz de transformar a realidade e a si mesmo (FERNANDEZ, 2001, p. 82).

Para tanto, prossegue a autora, é preciso que se constituam muito mais espaços de pergunta do que de respostas. Desenvolver a inteligência não tem tanto a ver com adaptar-se, mas, sim, a um movimento de desadaptação criativa, que ocorre à medida que o sujeito, ao interpretar o real, deseja e necessita perguntar: indaga possibilidades, indaga os porquês, o que não entendeu, a razão das diferenças (...) . Nisso, há identificação com o outro (ensinante), mas capacidade, sem culpa, de diferenciar-se e perceber-se na alteridade - eu-outro (FERNANDEZ, 2001).

No caso de sujeitos com deficiência na expressão verbal, é preciso significá-los - ou ressignificá-los - como intelectualmente capazes e com possibilidade de enunciação de linguagem (por quaisquer vias consideradas alternativas). O mediador deve ser interlocutor e proporcionar recursos comunicativos para conferir voz a essas pessoas, mas a interlocução precisa produzir sentidos, motivações, desafios e conflitos para fazer-se suficientemente mediadora, de modo que o sujeito enuncie e enuncie-se (autoria / subjetividade) e não haja aprisionamento das possibilidades e potencialidades comunicativas, pois:

A produção de sentidos é responsável por vínculos contraditórios, mas autênticos, e que crescem no diálogo. A eliminação do sentido subjetivo acarreta a eliminação do diálogo, a delimitação dos sujeitos se desvanece e é substituída por espaço social monolítico dirigido desde uma posição de poder, no qual o que parece como unidade está definido pelo medo e subordinação (GONZÁLEZ REY, 2004, p. 23).

O mediador pode ser considerado, assim, o primeiro recurso ou signo no estabelecimento de uma comunicação ampliada. Essa perspectiva não reflete somente um ângulo acadêmico de concepção de linguagem, mas reflete-se na mudança de olhar para o sujeito e para a própria atuação profissional e mediadora. 
Quando dirigimos o olhar para as singularidades do sujeito e a opacidade do dizer, os procedimentos de avaliação e intervenção clínicos assumem outra configuração. Damos lugar para os processos de subjetivação e a para a heterogeneidade, abrindo espaço para a polissemia os múltiplos sentidos do trabalho a ser produzido com e para o sujeito específico (PASSOS, 2007, p. 33).

Pontuamos que a opacidade está também, como na palavra, presente nos signos da CAA. Um significante nunca é transparente e de significado fixo, pois sua significação é potencialmente polissêmica; só ganha sentido(s) no interjogo dos falantes, no contexto em que enunciados são valorados e interpretados. Desse modo, é o enunciado, como afirma Bakhtin (1995), e não a palavra ou signo isolado, a menor unidade de análise na comunicação e dele decorrem produções discursivas a serem dialogadas no social.

\section{Obstáculos à interlocução mediadora}

A deficiência na expressão verbal não acarreta, em si mesma, limitação cognitiva e não deveria determinar intervençôes segregadas ou restritivas, seja quanto à convivência com falantes, seja quanto ao conteúdo de linguagem (minimização, seleção ou diluição). É difícil, no entanto, romper com estigmas historicamente constituídos em relação à condição de deficiência e que constituem a história e a formação de profissionais e familiares; estão presentes; portanto, parafraseando González Rey, nas subjetividades individuais e social.

Mesmo com o uso tecnicamente correto dos recursos da CAA e considerando as intenções, condições e interesses do sujeito, há o risco de se constituir uma deficiência circunstancial e um assujeitamento, pela restrição de enunciados, contextos linguísticos, interlocuções e mediações. A esse respeito destacamos posicionamentos que podem atuar como obstáculos ao desenvolvimento da enunciação autora:

a) Compreensão de linguagem como código alfabético ou como competência correspondente à fala para ser adquirida passo a passo.

A aquisição poderá ocorrer com êxito, mas limitado à memorização, expressão e uso funcional, nem sempre ou com pouca ênfase em situações desafiadoras que fomentem e propiciem o exercício da linguagem em práticas sociais na cultura, em situaçóes menos planificadas, com direito a variaçóes de contextos e diálogos com falantes mediante os quais o sujeito perceba e exercite 
a polissemia e constitua, assim, seu logos (nesta acepção, compreendido como linguagem e pensamento em interconstituição).

Como postula Vygotsky (1998), a aprendizagem deve estar além do desenvolvimento, exatamente como desafio para potencializá-lo.

b) Justificativas de restrição de interações ou mesmo da não introdução de determinados recursos que poderiam favorecer a comunicação, com base em determinado quadro clínico. Exemplos: ele não interage porque é autista ou não fala porque é PC (paralisado cerebral).

Assim, ainda que se vislumbre uma possibilidade de comunicação alternativa, esta é introduzida na expectativa de que o recurso propicie alguma expressão de linguagem e contribua para relativa autonomia, porém espera-se e investe-se muito mais em termos funcionais (dar respostas a...) do que no desenvolvimento da expressão subjetiva, partindo-se do pressuposto: condição orgânica deficiente necessariamente limita aprendizagens mais complexas. Ignora-se, portanto, o quanto a circulação de significantes e significados da cultura (social) é constitutiva das enunciações individuais, produções de sentido e pensamento e, por isso, poderia potencialmente, sob mediação adequada, atenuar características ditas patológicas ou déficits.

\section{c) Acomodação aos resultados da intervenção}

Se o conteúdo / repertório de signos figurativos e o uso de pranchas de comunicação apresentam-se tão somente funcionais e adequados aos ambientes e situações do cotidiano, é possível que haja certa acomodação ao vocabulário e repertório de linguagem tanto por parte do próprio sujeito, que se acostuma a ser atendido e entendido sob um número restrito de significantes, como também por parte dos interlocutores mais frequentes que se satisfazem com a comunicação básica.

Essa barreira atitudinal talvez seja um dos maiores desafios à intervenção para o desenvolver e ampliar a enunciação. O não desenvolvimento, a perda ou a deficiência da fala remetem à necessidade de habilitação ou reabilitação dessa competência ou de uma equivalente (no caso, comunicação alternativa), o que demanda um aprendizado que, em geral, não ocorre em curto prazo nem se mostra imediatamente amplo e ágil no processo e conteúdos. Assim, quando é alcançado um repertório básico que permite comunicação, esse resultado é considerado suficientemente bom e até além das expectativas. Perante uma história de aprendizado lento e respostas demoradas (termos sempre 
comparativos com o dito normal), acredita-se que intelectualmente há um retardo ou déficit, o que nem sempre é verdade ou é menos significativo do que se possa sugerir. A tendência é considerar que o sujeito já aprendeu o bastante e até se superou, principalmente se adolescente ou adulto, e diante disso, não se deseja nem se exige mais.

Decorre também dessa acomodação e consequente "cristalização" das enunciaçōes aprendidas o risco do sujeito ser mais enunciado pelo outro do que enunciar. Gestos, movimentos e atos de enunciação (verbais e não verbais) que envolvem ou não os recursos figurativos passam a ser lidos e interpretados sob significação única pelos interlocutores, os quais acabam por cercear potenciais diálogos e produção de significados e sentidos. Tornam-se comuns comentários como: já sei o que ele quer dizer; sempre que ele fica / aponta / faz assim, quer dizer isso... Exemplificando: a ato de apontar para o símbolo (foto, figura, pictograma) indicativo de beber água nem sempre pode corresponder a estou com sede ou quero que me traga água; conforme o contexto, pode expressar quero ir para o lugar onde está a água, desejo que pode ainda estar relacionado a uma segunda intenção, como encontrar-se com alguém que está no ambiente onde fica o bebedouro.

Interaçōes, ainda que constantes e afetivas, nem sempre são suficientemente mediadoras. É fundamental que o sujeito, a partir e com os recursos comunicativos, interaja, expresse(-se) e seja compreendido em seu contexto imediato quanto às necessidades prementes para a autonomia. Porém, as possibilidades do intelecto humano e de expressão de linguagem transcendem um básico comunicativo. Os processos comunicativos e de interlocução precisam, sobretudo nos ambientes pedagógicos, assumir um caráter mediador, ou seja, provocador de desafios ao intelecto, à expansão do vocabulário, perguntas e escolhas e à extensão do diálogo. Há de se constituir, assim, contextos e vínculos de aprendizagem favorecedores do desenvolvimento das funções psíquicas superiores, do sujeito ator e autor de enunciados e sentidos subjetivos.

Nesse processo, a expressão da autoria é favorecida e a ampliação das possibilidades de dialogia por significantes figurativos torna-se também um desafio à criatividade, sensibilidade e interlocução do mediador.

\section{Considerações finais}

A limitação ou ausência da fala indicam necessidades educacionais especiais a serem atendidas e os recursos da CAA vêm ao seu encontro como forma de conferir voz ao não falante, mas que também se enuncia. A referência 
de aprendizado e diálogo para o sujeito não poderá ser, entretanto, um conteúdo limitado e permanente, e sim o amplo universo linguístico e cultural que convida a conhecer, participar e compartilhar conhecimentos, eventos, emoções, sentimentos, leituras, palavras, imagens, pessoas, ambientes e, assim, viabiliza pensamentos, intenções e ações autoras.

O compromisso terapêutico e (psico) pedagógico com o sujeito que apresenta limitaçōes ou ausência de fala é proporcionar expressão da linguagem (gestual, corporal, figurativa) e intervir de maneira mediadora na interlocução, ou seja, potencializar, no diálogo e na ação ensinante, a aprendizagem para o desenvolvimento intelectual mediante os recursos de comunicação do sujeito e para o sujeito, de forma a prevenir também um aprisionamento cognitivo, linguístico e da subjetividade, risco gerado pelo uso limitado e indevido do recurso alternativo; recurso que, como o próprio nome diz, precisa traduzirse não em mera alternativa de comunicação, mas, sim, em comunicação ampliada.

\section{Referências}

BAKHTIN, M. Marxismo e Filosofia da Linguagem. 7. ed. São Paulo: Hucitec, 1995.

CHAUÍ, M. Introdução à História da Filosofia. v. 1: Dos Pré-socráticos a Aristóteles. São Paulo: Brasiliense, 1995.

CUNHA, A. G. Dicionário Etimológico Nova Fronteira da Lingua Portuguesa. Rio de Janeiro: Nova Fronteira, 1997.

CUPOLILlO, M.; FREITAS, A. B. M. Diferença: condição básica para a constituição do sujeito. Revista da Associação Brasileira de Psicologia Escolar e Educacional. São Paulo, v. 11, n. 2, p. 379-390, 2007.

FERNÁNDEZ, A. O saber em jogo: a psicopedagogia proporcionando autorias de pensamento. Porto Alegre: Artmed, 2001.

FREITAS, A.B.M. A mediação lúdica no espectro autista: uma possibilidade comunicativa e de intervenção psicopedagógica. Revista Educação Especial. Santa Maria, v. 22, n. 33, p. 41-58, 2009.

GOMES, C.; GONZÁLEZ REY, F. L. Psicologia e inclusão: aspectos subjetivos de um aluno portador de deficiência mental. Revista Brasileira de Educação Especial. Marília, v. 14, n. 1, p. 53-62, 2008. 
GONZÁLEZ REY, F. O sujeito, a subjetividade e o outro na dialética complexa do desenvolvimento humano: diálogos para a pesquisa e a prática profissional em psicologia. In: SIMÃO, L.M.; MITJÁNS, A.M. (Org.). O outro no desenvolvimento humano. São Paulo: Thomson, 2004. p.1-28.

MANZINI, E. J.; DELIBERATO, D. Portal de Ajudas Técnicas para educação: equipamento e material pedagógico especial para educação, capacitação e recreação da pessoa com deficiência física: recursos para comunicação alternativa. Brasília: MEC, Secretaria de Educação Especial, 2006. 52 p. ISBN 85-86738-26-3

MAYER-JOHNSON Produtos para Comunicação Alternativa. Disponível em: Clik Tecnologia Assistiva. <http://www.clik.com.br/mj_01.html\#boardmaker>. Acesso em: 8 mar. 2011.

ORRÚ. S. E. Autismo, linguagem e educação: interação social no cotidiano escolar. Rio de Janeiro: Wak, 2007.

PADILHA, A. M. L. Práticas pedagógicas na educação especial: a capacidade de significar o mundo e a inserção cultural do deficiente mental. Campinas: Autores Associados, 2001.

PASSOS, P. M. P. A construção da subjetividade através da interação dialógica pela comunicação suplementar e a alternativa. 2007, 117f. Dissertação (Mestrado em Educação) - Faculdade de Ciências Humanas, Universidade Metodista de Piracicaba, Piracicaba, 2007.

PELOSI, M. B. A comunicação alternativa e ampliada nas escolas do Rio de Janeiro: formação de professores e caracterização dos alunos com necessidades educacionais especiais. 2000, 225f. Dissertação (Mestrado em Educação) Faculdade de Educação, Universidade Estadual do Rio de Janeiro, Rio de janeiro, 2000.

VYGOTSKY, L.S. A Formação social da mente: o desenvolvimento dos processos psicológicos superiores. 6. ed. São Paulo: Martins Fontes, 1998.

VYGOTSKY, L.S. A construção do pensamento e da linguagem. São Paulo: Martins Fontes, 2001.

Recebido em 27/7/2011. Aprovado em 19/9/2011. 